\title{
ESTUDO DA APLICAÇÃO DO CACTO Opuntia cochenillifera NO TRATAMENTO DE ÁGUA
}

\author{
Higgor Henrique Dias Goes ${ }^{1}$; Rita de Cássia Pereira de Souza ${ }^{2}$; Jessica Muniz \\ De Melo ${ }^{3}$; Joseane Débora Peruço Theodoro ${ }^{4}$ \\ ${ }^{1}$ Discente de Engenharia Ambiental - UTFPR- Londrina, Brasil \\ (higgorgoes@alunos.utfpr.edu.br) \\ ${ }^{2,3}$ Discente de Engenharia Ambiental - UTFPR \\ ${ }^{4}$ Professora Doutora do Departamento Acadêmico de Ambiental - UTFPR
}

Recebido em: 08/04/2017 - Aprovado em: 10/06/2017 - Publicado em: 20/06/2017 DOI: 10.18677/EnciBio_2017A50

\begin{abstract}
RESUMO
Objetivou-se com a realização do presente estudo utilizar o polímero orgânico cacto Opuntia cochenillifera para tratar a água de um corpo lêntico (Lago Igapó II) aplicando os processos de coagulação, floculação, sedimentação e filtração. Os testes foram realizados com reator estático Jar-test, para avaliar a remoções dos parâmetros turbidez e cor aparente, além de acompanhar a variação do $\mathrm{pH}$. Em relação às características físico-químicas, houve pouca influência do cacto Opuntia cochenillifera no parâmetro $\mathrm{pH}$. Então, o estudo mostrou que a utilização do coagulante orgânico é eficaz para as remoções dos parâmetros cor aparente e turbidez (97 e 96\%, respectivamente), além de ter matéria-prima em abundância na região nordeste brasileira e possuir custo menor quando comparado com os coagulantes inorgânicos comercializados.
\end{abstract}

PALAVRAS-CHAVE: cactos, coagulante orgânico, tratamento de água.

\section{STUDY OF THE APPLICATION OF THE CACTUS OPUNTIA COCHENILLIFERA IN WATER TREATMENT}

\begin{abstract}
The aim of the present study to use the organic polymer, cactus Opuntia Cochenillifera to the water treatment in a lentic water (Igapó II lake) applying the coagulation, flocculation, sedimentation and filtration processes. The samples were made with the Static Jar-test reactor, in order to evaluate the removal of the apparent color parameter and the turbidity parameter, besides to keep up with the $\mathrm{pH}$ variation. Regarding the physicochemical characteristics, there was little influence of cactus Opuntia Cochenillifera at the $\mathrm{pH}$ parameter. Then, this research showed that the organic coagulant is efficient to removal of the apparent color parameter and the turbidity parameter, (97 e $96 \%$, respectively), moreover there is abundance of it, in the northeast of Brazil, and it has a reduced cost, when compared to inorganic coagulants marketed.
\end{abstract}

KEYWORDS: cacti, organic coagulant, water treatment. 


\section{INTRODUÇÃO}

A água para tornar-se própria ao consumo humano de modo a não provocar danos à saúde de seus consumidores deve apresentar uma qualidade que satisfaça as condições exigidas na legislação, como a PORTARIA № 2.914/2011 que dispõe sobre os procedimentos de controle e de vigilância da qualidade da água para consumo humano e seu padrão de potabilidade (BRASIL, 2011).

As etapas do tratamento da água bruta envolvem o processo de clarificação que consiste basicamente na remoção de sólidos. Os sólidos em suspensão são removidos por sedimentação simples ou sedimentação por coagulação e filtração. A clarificação tem como função principal a remoção da turbidez, e para a obtenção da água clarificada é preciso empregar técnicas ou operações, tais como a coagulação, floculação, sedimentação e filtração (SANESUL, 2016).

Como alternativa para a obtenção de água potável, pode-se adotar agentes naturais como os coagulantes à base de taninos, cactos e Moringa oleifera, que possuem eficiência igual ou superior aos sais metálicos em alguns parâmetros, além da menor toxicidade do lodo gerado. Satisfatoriamente, os cactáceos apresentam-se como alternativa para indústrias com escassez de recursos financeiros (YIN, 2010). Polímeros obtidos de fontes naturais, quando aplicados como coagulantes primários ou auxiliares se apresentam como alternativas viáveis para substituir ou reduzir o uso de coagulantes metálicos devido ao seu baixo custo e por abundância de plantas que podem se apresentar como fonte para extração (THEODORO et al., 2013).

A mucilagem de um cacto comum é usada para eliminar a turbidez em água potável. Além disso, é derivado de um recurso renovável e sua disposição irá envolver a degradação orgânica simples (PICHLER; ALCANTAR, 2012). Estudos afirmam os benefícios da mucilagem das plantas Cactáceas quando avaliado as propriedades do cacto (Opuntia ficus-indica) como coagulante natural para a clarificação de águas turvas (VERBEL et al., 2014).

Conhecida como palma, a cactácea forrageira Opuntia cochenillifera é difundida no nordeste brasileiro e possui origem mexicana. Entre suas características, se destaca a forma xeromorfa com caule cilíndrico e seus ramos conhecidos como palmas. A utilização atualmente dessa planta varia desde alimentação animal e humana, quanto a projetos paisagísticos e extração de corantes (VERBEL et al., 2014).

Desta forma, objetivou-se com a realização deste trabalho analisar a qualidade da água do lago Igapó II da cidade de Londrina-PR, segundo os parâmetros cor aparente e turbidez, além de realizar o tratamento dessas águas através do processo de coagulação/floculação/sedimentação/filtração com uso do cacto Opuntia cochenillifera como coagulante orgânico, verificando a possibilidade de uso dessas águas lênticas para abastecimento urbano.

\section{MATERIAL E MÉTODOS}

Foram utilizadas amostras de água adquiridas a partir da área de estudo do Lago Igapó II, localizado na cidade de Londrina, estado do Paraná, Brasil. O Lago Igapó II está a 550 metros acima do nível do mar. As coordenadas do ponto de coleta são $23^{\circ} 19^{\prime} 42^{\prime \prime} \mathrm{S}$ e $51^{\circ} 10^{\prime} 11^{\prime \prime} \mathrm{O}$. A Figura 1 representa espacialmente a localização do ponto destacado para a coleta das amostras. 


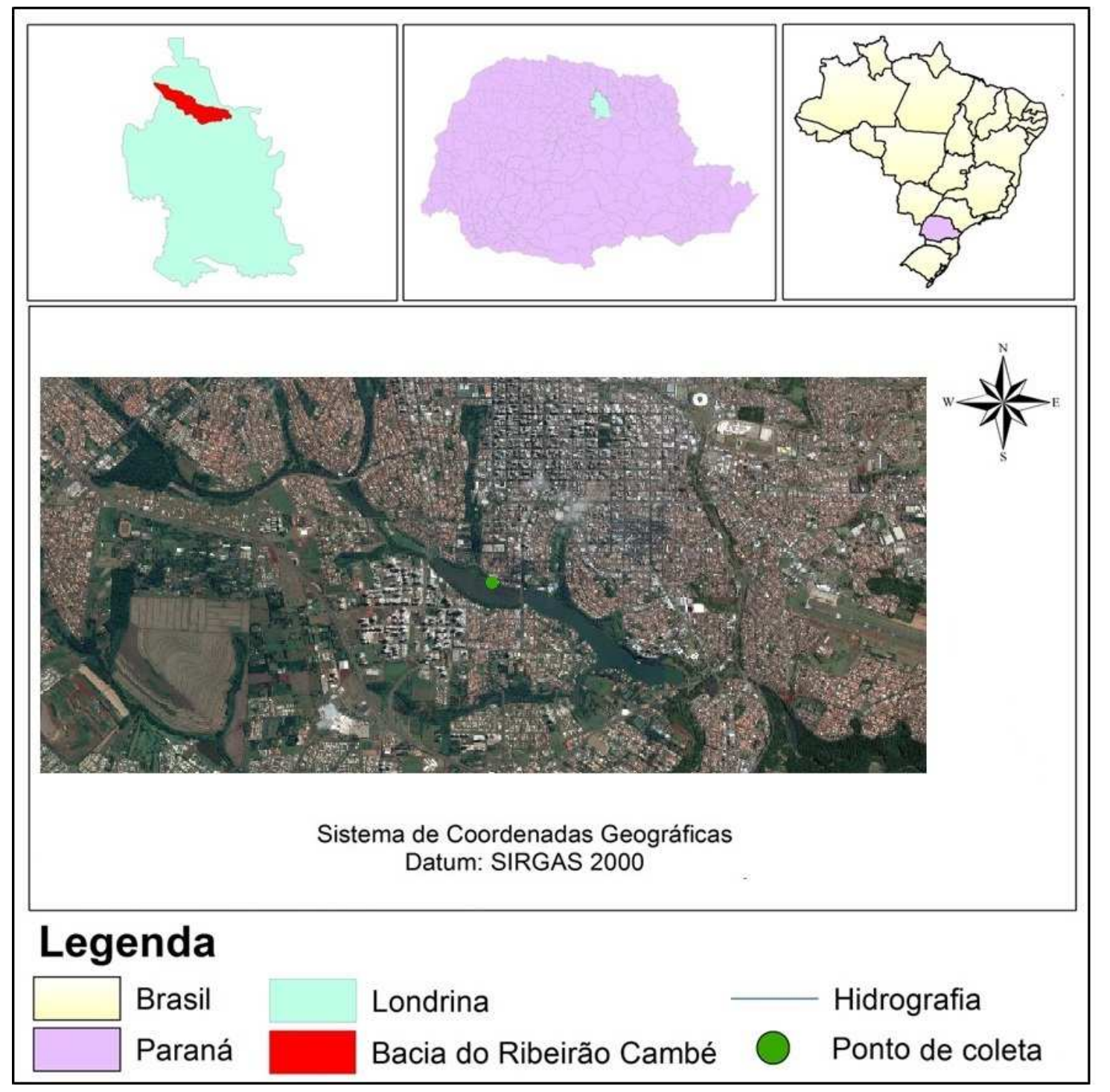

FIGURA 1 - Localização espacial do ponto de coleta no Lago igapó II. Fonte: Autores (2016).

O Lago foi projetado em 1957, como uma solução para o problema da drenagem do ribeirão Cambezinho, dificultada por uma barragem natural. O mesmo foi inaugurado em 1959 (PREFEITURA MUNICIPAL DE LONDRINA, 2016). A área de estudo é caracterizada como sistema lêntico, na qual a principal característica do mesmo é a alta capacidade em solubilizar compostos orgânicos, além de apresentar baixo teor de sais dissolvidos e alta densidade e viscosidade da água (ESTEVES, 2011). Foi realizada a amostragem de 72 litros de água do Lago Igapó II e armazenou-se em galões plásticos higienizados.

A metodologia para a extração do polímero ocorreu em duas etapas. A primeira consistiu na retirada dos espinhos e na limpeza (retirada da casca), na qual realizou-se os cortes e a liquidificação. A segunda preparou-se dois litros da solução de extração por meio de um litro de água destilada com $4 \mathrm{~g}$ de soluções de cloreto de sódio $1 \%$ e um litro de água destilada com $10 \mathrm{~g}$ hidróxido de sódio $0,10 \mathrm{~mol} \mathrm{~L}^{-1}$ (Zara et al., 2012). A relação foi de um $\mathrm{mL}$ de cacto preparado para $2,5 \mathrm{~mL}$ da solução de extração, cuja mistura era homogeneizada em agitador magnético marca Nova Ética, modelo 114, durante 40 minutos. O complexo viscoso resultante foi acondicionado em frascos higienizados de vidro e armazenados sobre refrigeração à ENCICLOPÉDIA BIOSFERA, Centro Científico Conhecer - Goiânia, v.14 n.25; p.556 
5C até a realização dos ensaios no equipamento JarTest. Alguns desses passos são apresentados na Figura 2.
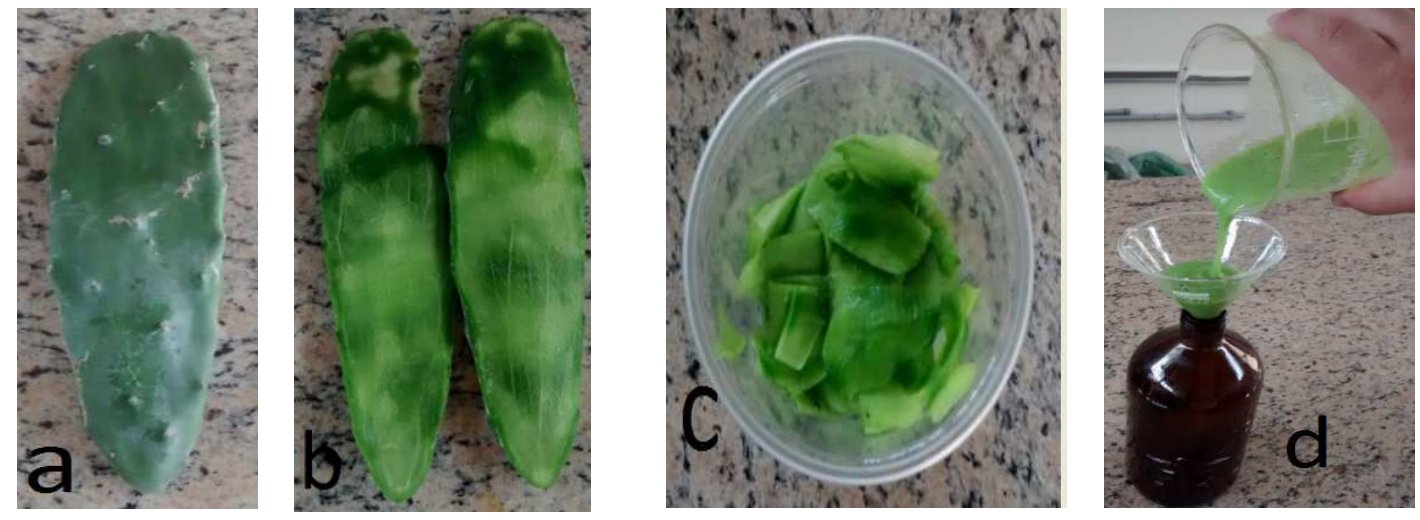

FIGURA 2 - a) Palma da Opuntia cochenillifera; b) Retirada da casca; c) Corte para posterior liquidificação; d) Armazenamento do complexo viscoso.

Fonte: autores.

Para o ajuste dos valores de $\mathrm{pH}$, a fim de torná-lo ácido $(\mathrm{pH}=4,87)$, utilizou-se a solução de ácido clorídrico $(\mathrm{HCl})$, concentração $1 \mathrm{M}$. Enquanto para a amostra com $\mathrm{pH}$ básico $(\mathrm{pH}=9,08)$, foi utilizada a solução de hidróxido de sódio $(\mathrm{NaOH})$, na concentração $1 \mathrm{M}$. O valor do pH neutro da amostra bruta foi de 7,65.

Para o experimento, as dosagens do coagulante cactos (Opuntia cochenillifera) foram $1 \mathrm{mg} \mathrm{L}^{-1}, 4 \mathrm{mg} \mathrm{L}^{-1}$ e $7 \mathrm{mg} \mathrm{L}^{-1}$. Nos ensaios do tratamento da água de estudo pelos processos de coagulação/floculação/sedimentação, foi utilizado o equipamento jar-test de seis provas com regulador de rotação das hastes misturadoras. Na Tabela 1 são apresentados os parâmetros utilizados nos processos de coagulação/floculação.

TABELA 1 - Gradiente de rotação das hastes misturadoras e tempo de ação.

\begin{tabular}{ccccc} 
Mistura Rápida & Mistura Lenta & Mistura Lenta & Mistura Lenta & Mistura Lenta \\
& $\mathbf{1}$ & $\mathbf{2}$ & $\mathbf{3}$ & $\mathbf{4}$ \\
Gradiente $\left(\mathbf{s}^{-1}\right)$ & Gradiente $\left(\mathbf{s}^{-1}\right)$ & Gradiente $\left(\mathbf{s}^{-1}\right)$ & Gradiente $\left(\mathbf{s}^{-1}\right)$ & Gradiente $\left(\mathbf{s}^{-1}\right)$ \\
\hline 450 & 90 & 52 & 40 & 30 \\
\hline Tempo $(\mathbf{m i m})$ & Tempo $(\mathbf{m i m})$ & Tempo $(\mathbf{m i m})$ & Tempo $(\mathbf{m i m})$ & Tempo $(\mathbf{m i m})$ \\
\hline $00: 10$ & $02: 00$ & $02: 35$ & $02: 40$ & $05: 40$ \\
\hline
\end{tabular}

Fonte: HIGASHI (2016).

Para os ensaios de coagulação/floculação/sedimentação, foi adotado um tempo para sedimentação de 10 minutos. Ao final do tempo estabelecido para sedimentação, foram realizadas coletas de todos os ensaios e foram medidos os parâmetros cor aparente, turbidez e $\mathrm{pH}$.

Para o ensaio de filtração foi utilizada uma estrutura de ferro adaptada para fixar os filtros de areia abaixo do jar-teste de forma que a água saia do aparelho diretamente para os filtros. Os leitos filtrantes apresentam-se confeccionados de Polietileno Tereftalato (PET) de aproximadamente $10 \mathrm{~cm}$ de diâmetro interno configurando um modelo de leito fixo com fluxo descendente, com seis colunas em paralelo, como observado na Figura 3. 


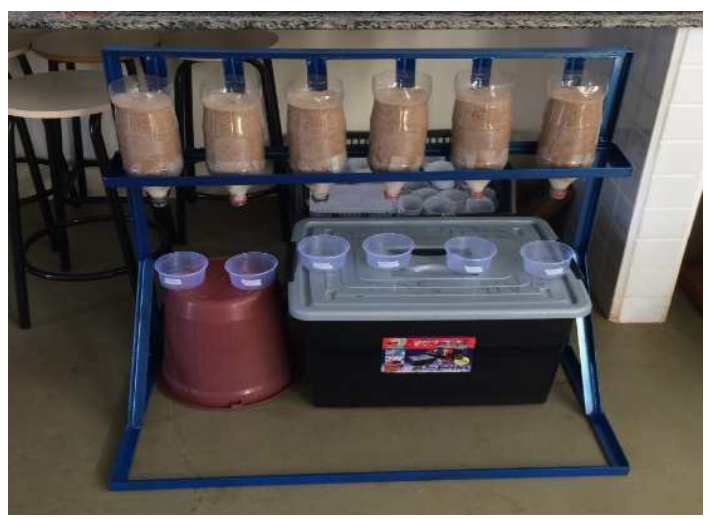

a) Colunas de filtração utilizadas no ensaio.

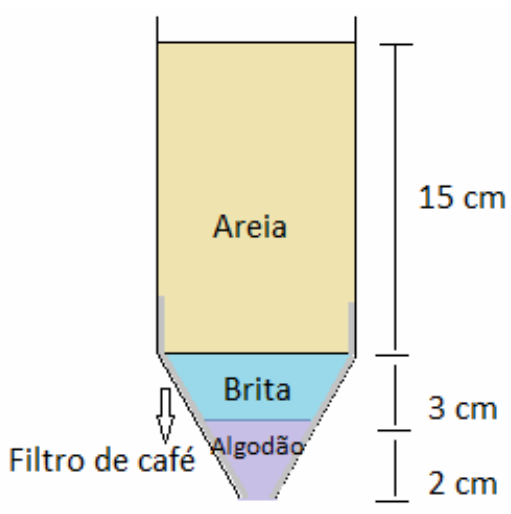

b) Modelo representativo das camadas do filtro.

FIGURA 3 - Processo de filtração.

Fonte: Autores

Os tubos possuem $25 \mathrm{~cm}$ de comprimento com $15 \mathrm{~cm}$ preenchidos por areia, $3 \mathrm{~cm}$ preenchidos por brita e $2 \mathrm{~cm}$ preenchidos por algodão. As granulométricas da areia utilizada nos 6 filtros foram as mesmas, na faixa de 0,60 à $0,85 \mathrm{~mm}$. A inclinação utilizada na saída do jar-teste foi de $70^{\circ}$ durante dois minutos, seguidos de mais dois minutos com a angulação de $60^{\circ}$ e mais dois minutos $50^{\circ}$ (DI BERNARDO et al., 2003).

A água a ser tratada entrou pelo topo da coluna e seu sobrenadante retirado foi pela lateral. Os grãos do leito filtrante foram retidos por um filtro de café juntamente com a camada de algodão e brita presente na extremidade inferior da coluna.

Para todas as variações de concentrações de cactos e pH foram determinados os parâmetros de cor aparente e turbidez de acordo com o Standard Methods of Examination of Waterand Wastewater (APHA, 2012). Nesse trabalho foi utilizado um planejamento estatístico com dois fatores (variáveis independentes), a concentração do coagulante cactos e três parâmetros respostas (cor aparente, turbidez e $\mathrm{pH}$ ), os ensaios foram realizados em duplicatas.

\section{RESULTADOS}

Após o tratamento foram realizados os cálculos de remoção dos parâmetros, cor aparente e turbidez e o acompanhamento do $\mathrm{pH}$ para os processos coagulação/floculação/sedimentação/filtração. Os valores encontrados são apresentados na Tabela 2. A Figura 4 representa a água bruta e após tratamento coagulação/floculação/sedimentação e filtração. 
TABELA 2 - Organização numérica dos ensaios para diferentes níveis de concentração de coagulante e pH com valores reais e resultados dos parâmetros cor, turbidez e pH

\begin{tabular}{|c|c|c|c|c|c|c|c|c|c|c|}
\hline Ensaio & $\begin{array}{l}\text { Cacto } \\
\text { (mg/L) }\end{array}$ & $p H$ & $\begin{array}{c}\text { Cor } \\
(C / F / S) \\
\%\end{array}$ & $\begin{array}{l}\text { Cor } \\
\text { (Fi) } \\
\%\end{array}$ & $\begin{array}{c}\text { Cor } \\
(C / F / S / F i) \\
\%\end{array}$ & $\begin{array}{c}T \\
(C / F / S) \\
\%\end{array}$ & $\begin{array}{c}T \\
(F i) \\
\%\end{array}$ & $\begin{array}{c}T \\
(C / F / S / F i) \\
\%\end{array}$ & $\begin{array}{c}p H \\
(C / F / S)\end{array}$ & $\begin{array}{c}p H \\
(C / F / S / F i)\end{array}$ \\
\hline 1 & 1 & 4,87 & -10 & 88 & 86 & 17 & 85 & 87 & 6,95 & 7,67 \\
\hline 2 & 1 & 7,85 & 60 & 73 & 89 & 49 & 71 & 86 & 7,89 & 8,12 \\
\hline 3 & 1 & 9,08 & 5 & 89 & 89 & 2 & 91 & 91 & 7,36 & 8,27 \\
\hline 4 & 4 & 4,87 & -3 & 94 & 94 & 26 & 94 & 95 & 7,00 & 7,57 \\
\hline 5 & 4 & 7,85 & 60 & 73 & 89 & 49 & 73 & 86 & 7,85 & 8,06 \\
\hline 6 & 4 & 9,08 & 8 & 92 & 93 & 14 & 89 & 91 & 7,44 & 7,9 \\
\hline 7 & 7 & 4,87 & -12 & 94 & 94 & 22 & 95 & 96 & 7,95 & 7,72 \\
\hline 8 & 7 & 7,85 & 57 & 71 & 88 & 51 & 70 & 86 & 7,88 & 8,07 \\
\hline 9 & 7 & 9,08 & -1 & 93 & 93 & 1 & 90 & 90 & 6,98 & 7,96 \\
\hline 10 & 1 & 4,87 & -11 & 93 & 92 & 18 & 93 & 94 & 6,63 & 7,6 \\
\hline 11 & 1 & 7,85 & 57 & 78 & 91 & 48 & 76 & 88 & 7,45 & 8,1 \\
\hline 12 & 1 & 9,08 & 2 & 93 & 93 & 2 & 90 & 91 & 7,66 & 7,88 \\
\hline 13 & 4 & 4,87 & -5 & 95 & 95 & 26 & 95 & 96 & 7,25 & 7,6 \\
\hline 14 & 4 & 7,85 & 59 & 75 & 90 & 50 & 75 & 87 & 7,71 & 8,02 \\
\hline 15 & 4 & 9,08 & 3 & 97 & 97 & 2 & 95 & 95 & 7,6 & 8,4 \\
\hline 16 & 7 & 4,87 & 7 & 92 & 92 & 19 & 93 & 94 & 6,5 & 7,56 \\
\hline 17 & 7 & 7,85 & 58 & 70 & 88 & 48 & 70 & 85 & 7,36 & 8,14 \\
\hline 18 & 7 & 9,08 & 6 & 89 & 89 & -2 & 88 & 87 & 7,69 & 7,87 \\
\hline
\end{tabular}

OBS: $\mathrm{C} / \mathrm{F} / \mathrm{S}=$ coagulação/floculação/sedimentação; Fi= filtração;

$\mathrm{C} / \mathrm{F} / \mathrm{S} / \mathrm{Fi}$ = coagulação/floculação/sedimentação/filtração. Fonte: Autoria própria.

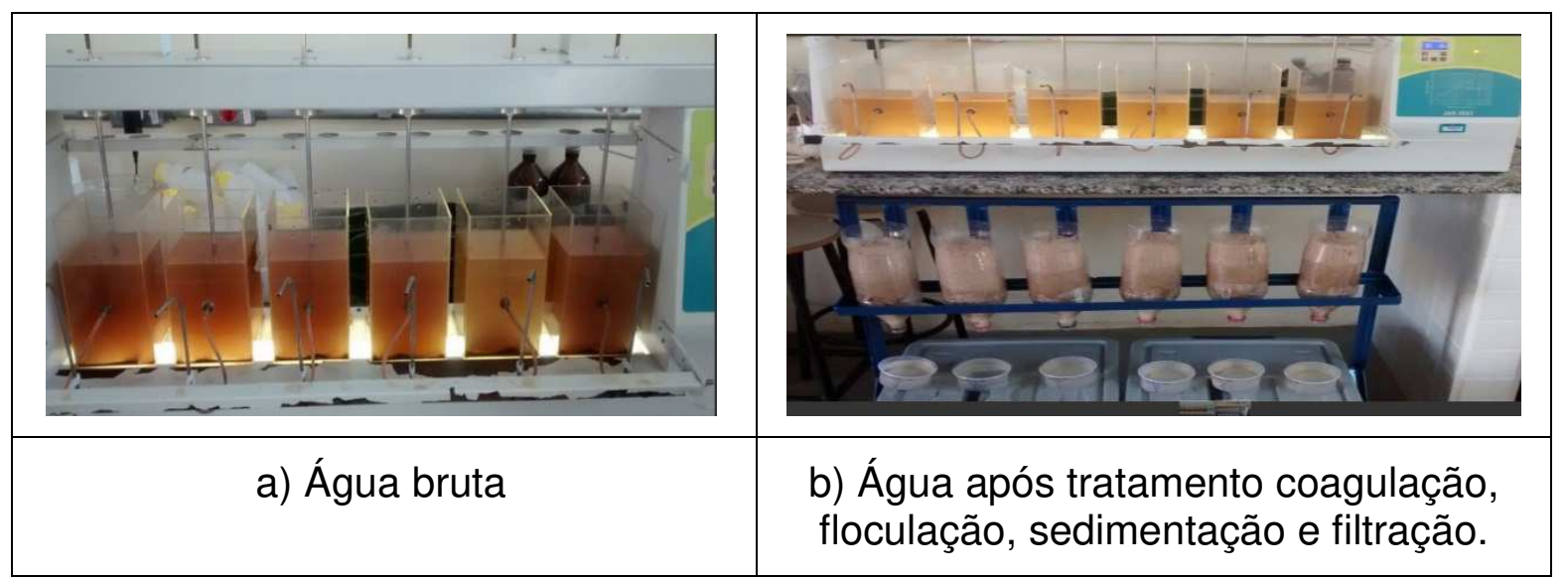

FIGURA 4 - Diferença visual da água bruta e após o tratamento Fonte: Autores

As Figuras 5, 6 e 7 mostram as remoções do parâmetro cor aparente e turbidez para os processos de coagulação/floculação/sedimentação, somente filtração e para o processo completo (coagulação/floculação/sedimentação/filtração), respectivamente. 


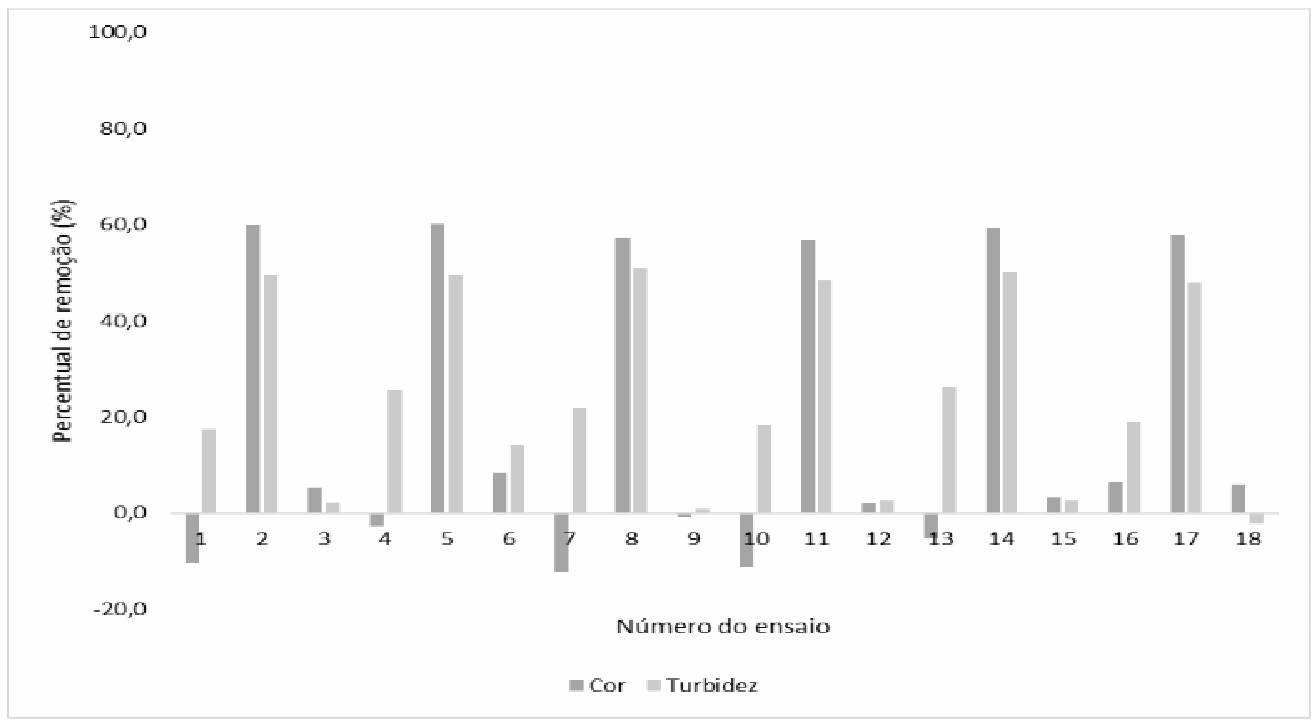

FIGURA 5 - Remoção de cor aparente e turbidez após o processo de Coagulação/Floculação/Sedimentação.

Analisando a Figura 5, percebe-se que os melhores resultados apresentados estão associados com os valores de $\mathrm{pH}$ neutro (ensaios 2, 5, 8, 11, 14 e 17), removendo aproximadamente $60 \%$ da cor e $50 \%$ da turbidez. É possível verificar nos ensaios 1, 4, 7, 10 e 13, que o coagulante orgânico cacto se dissolveu na solução aumentando os sólidos dissolvidos, justificando assim, os valores negativos de porcentagem de remoção do parâmetro cor.

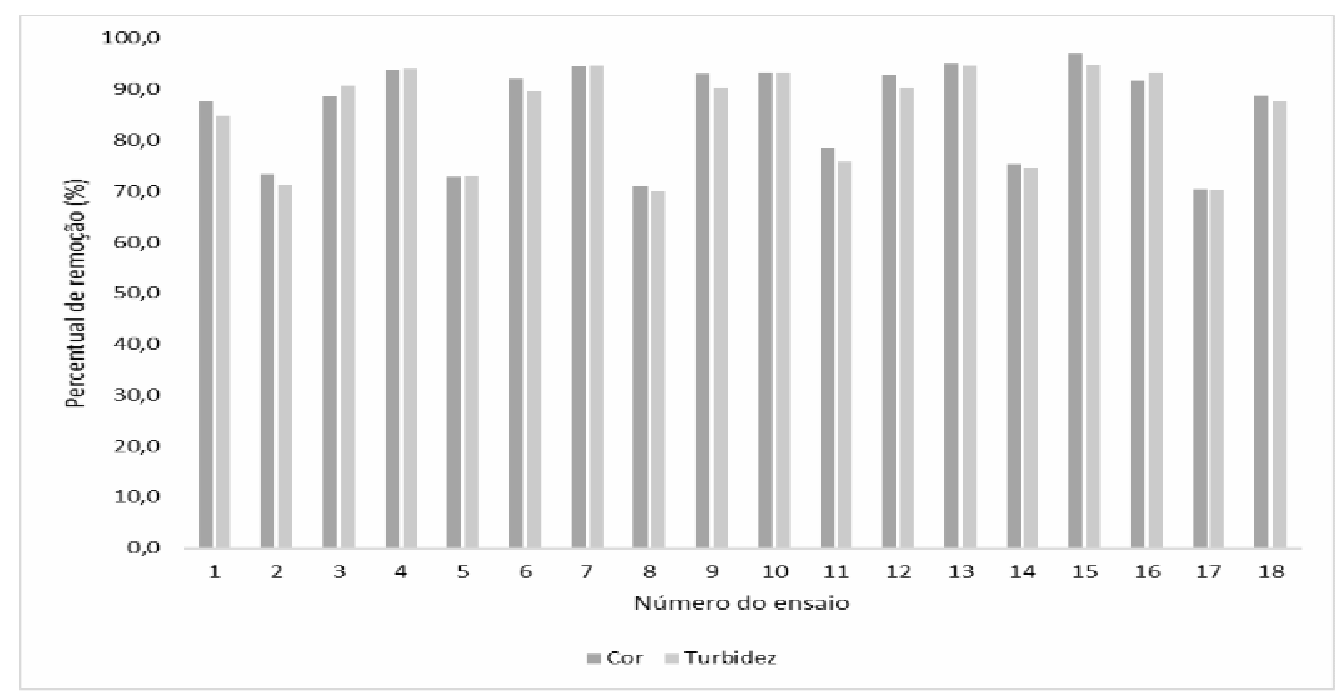

FIGURA 6 - Remoção de cor aparente e turbidez no processo de filtração.

$O$ processo de filtração demonstrou-se mais eficiente para os valores de $\mathrm{pH}$ básico e ácido, permitindo uma remoção maior que $85 \%$ nos dois parâmetros analisados. 


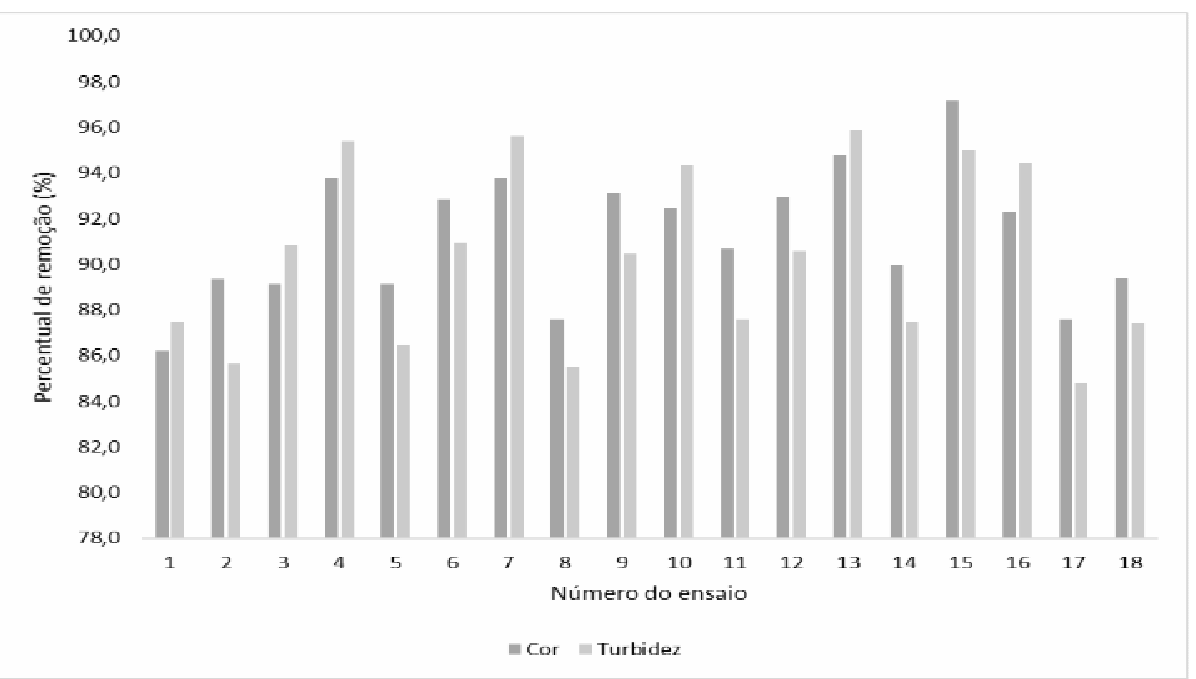

FIGURA 7 - Remoção de cor aparente e turbidez após o processo de Coagulação/Floculação/Sedimentação/Filtração.

Com a realização do processo completo, notou-se que todos os ensaios obtiveram valores de remoção de cor e turbidez acima de $85 \%$. Assim, analisando os resultados apresentados pode-se concluir que tanto os processos de coagulação/floculação/sedimentação (Figura 5), quanto o processo de filtração (Figura 6), são de grande importância para a remoção de cor turbidez no tratamento da água. Na Figura 7, os valores de remoção destes parâmetros ficaram acima de $95 \%$ para os ensaios 13 e 15, por exemplo.

Comparando os valores obtidos com os exigidos pela Portaria 2914/2011 do Ministério da Saúde (BRASIL, 2011), os ensaios não atenderam ao VMP (valor máximo permitido) de cor aparente e de turbidez. As Figuras 9 e 10, apresentam os resultados de variação de $\mathrm{pH}$, após os processos de coagulação/floculação/sedimentação e após 0 processo de coagulação/floculação/sedimentação/filtração com 0 uso do cacto (Opuntia Cochenillifera).

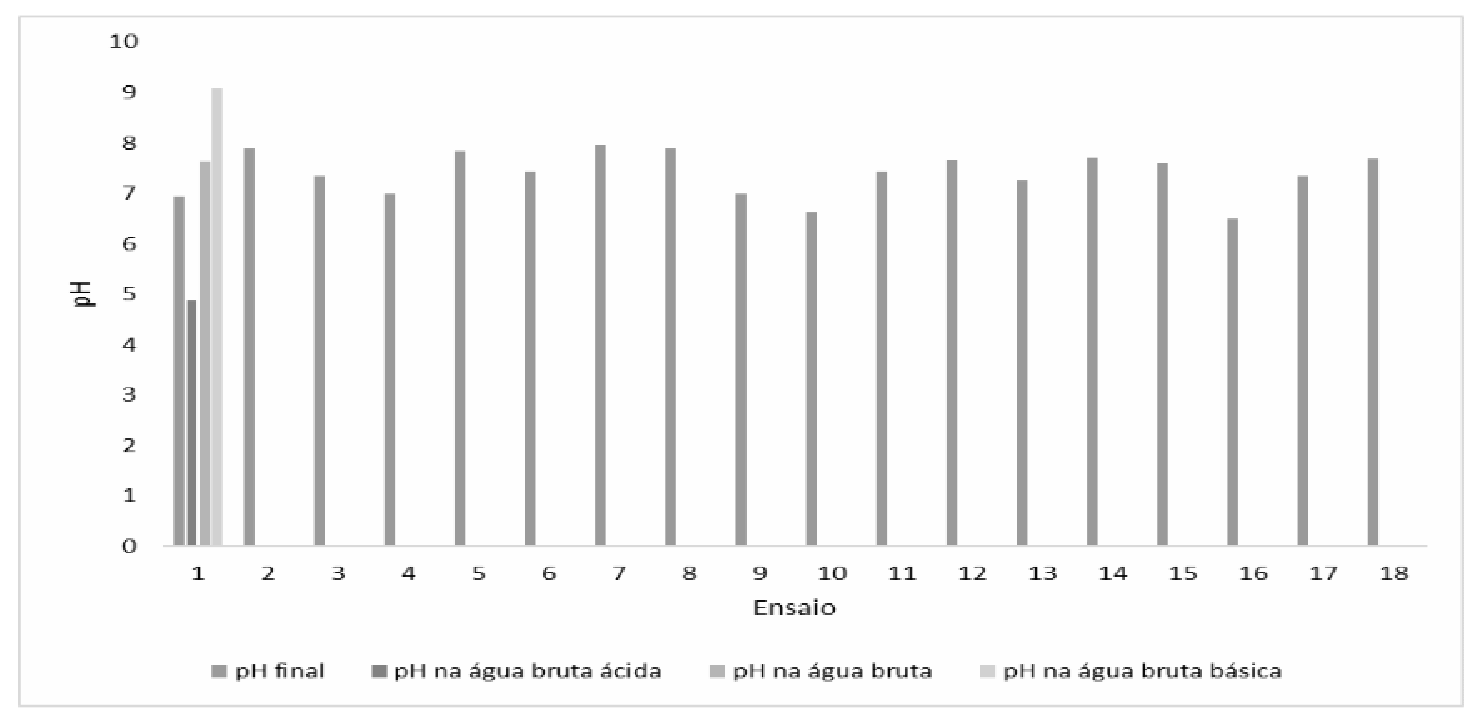

FIGURA 8 - pH após o processo de coagulação/floculação/sedimentação 
A figura 8 demonstra que após a coagulação/floculação/sedimentação $\circ$ pH dos ensaios ácidos e básicos tendem a atingir a neutralidade durante o processo e os ensaios que estavam nessa faixa permanecem.

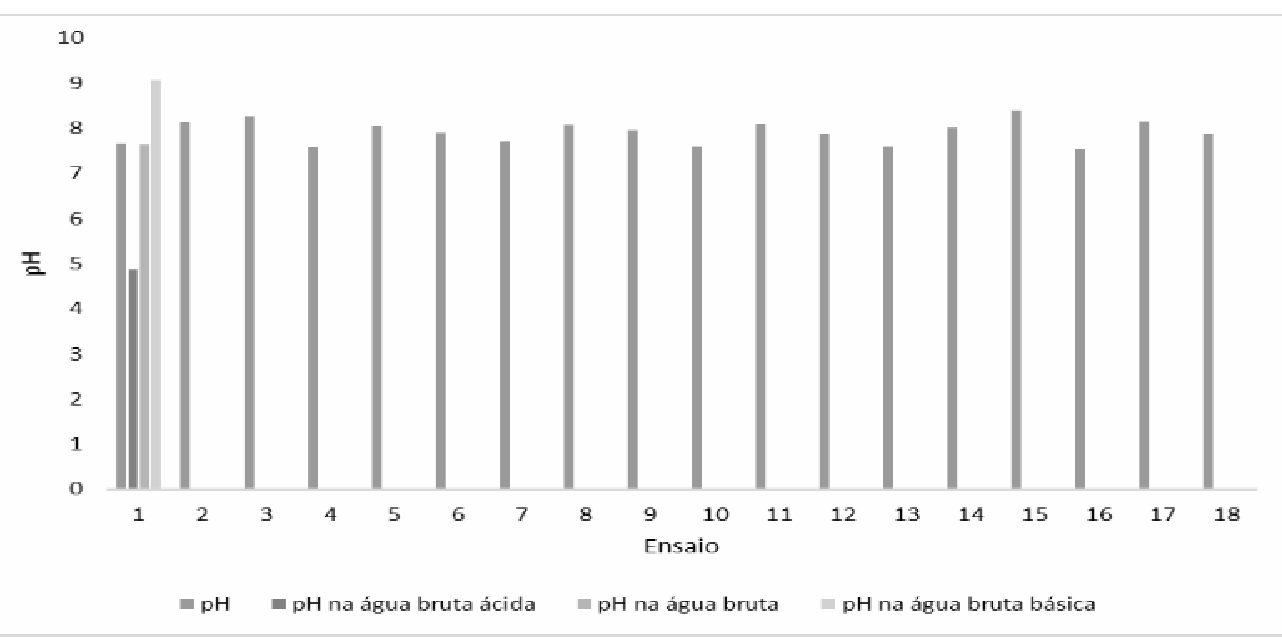

FIGURA 9 - pH após o processo de coagulação/floculação/sedimentação/filtração

Após passar também pela filtração (Figura 9), a água tende a obter valores mais próximos da neutralidade. Isso acorre devido a capacidade das partículas de areia em adsorver os componentes presentes na água, neutralizando $\mathrm{O} \mathrm{pH}$. Comparando os valores obtidos com os exigidos pela Portaria 2.914/2011(BRASIL, 2011) do Ministério da Saúde, todos os ensaios atenderam ao VMP de pH (6 a 9).

\section{CONCLUSÃO}

A solução coagulante obtida a partir do cacto Opuntia cochenillifera foi eficiente no tratamento da água proveniente do sistema lêntico Lago Igapó, mantendo o $\mathrm{pH}$ próximo da neutralidade.

\section{REFERÊNCIAS}

APHA - American Public Health Association. Standard Methods for the Examination of Water and Wastewater. 22 ed. Washington, 2012.

BRASIL, Ministério da Saúde. Portaria n. 2.914, de 12 de dezembro de 2011. Disponível em: http://bvsms.saude.gov.br/bvs/saudelegis/gm/2011/prt2914_12_12_2011.html

DI BERNARDO, L.; MENDES, C. G. N.; BRANDÃO, C. C. S.; SENS, M. L.; PÁDUA, V. L. Tratamento de Água para Abastecimento por Filtração direta. Luiz Di Bernardo (coordenador) - Rio de Janeiro: ABES, RiMa, 2003. Projeto PROSAB 498 p.

ESTEVES, F. A. Fundamentos de limnologia. 3 ed. Rio de Janeiro: Editora Interciência, 2011. 
HIGASHI V. Y.; THEODORO J. D. P.; PEREIRA E. R.; THEODORO P. S.; Uso De Coagulantes Químico (Cloreto Férrico) E Orgânico (Moringa Oleifera) No Tratamento De Águas Provenientes De Sistema Lêntico. Congresso Técnico Científico da Engenharia e da Agronomia - CONTECC'2016, 29 de agosto a 2 de setembro de 2016 - Foz do Iguaçu, Brasil. Disponível em: <http://www.confea.org.br/media/contecc2016/quimica/uso\%20de\%20coagulantes\% 20qu\%C3\%ADmico\%20(cloreto\%20ferrico)\%20e\%20org\%C3\%A2nico\%20(moringa $\% 20$ oleifera)\%20no\%20tratamento\%20de\%20\%C3\%A1guas\%20provenientes\%20d e\%20sistema\%201\%C3\%AAntico.pdf> Acesso em 07 Abril de 2016

PICHLER, T., YOUNG, K; ALCANTAR, N. Eliminating turbidity in drinking water using the mucilage of a common cactus. Water Science and Technology: Water Supply, v. 12, n.2, 179-186, 2012.

PREFEITURA DE LONDRINA. Lago Igapó. Disponível em: $<$ http://www.londrina.pr.gov.br/index.php?option=com_content\&view=article\&id=100 \&ltemid=112>. Acesso em 31 mai. de 2016.

SANESUL. Abastecimento de água: clarificação. Disponível em: <http://www.sanesul.ms.gov.br/conteudos.aspx?id=4>. Acesso em: 31 mai. 2016.

THEODORO, J. D. P.; LENZ, G. F.; ZARA, R. F.; BERGAMASCO, R.. Coagulants and Natural Polymers: Perspectives for the Treatment of Water. Plastic and Polymer Technology (PAPT), v. 2, Issue 3, September 2013.

VERBEL, R. E. O.; MENDONZA, Y. R. A.; MARTÍNEZ, I. D. M.; CAMARGO, D. P. C. GAZABÓN, L. E. Utilización de Tuna (opuntia ficus-indica) como coagulante natural en la clarificación de aguas crudas. Avances Investigación en Ingeniería, v.11, n.1, 1794-4953, 2014.

YIN, C. Emerging usage of plantObased coagulants for water na wastewater treatment. Process Biochemistry, v. 45, 2010.

ZARA, R. F.; THOMAZINI, M. H.; LENZ, G. F. Estudo da eficiência de polímero natural extraído do cacto mandacaru (Cereus jamacaru) como auxiliar nos processos de coagulação e floculação no tratamento de água. Revista de Estudos Ambientais (Online), v.14, n.2 esp, p.75-83, 2012. 